JAMA

Online article and related content current as of May 18, 2010.

\title{
Comparing Endovascular and Open Repair of Abdominal Aortic Aneurysm
}

\author{
Jan-Peter van Kuijk; Willem-Jan Flu; Don Poldermans
}

JAMA. 2010;303(6):513-514 (doi:10.1001/jama.2010.87)

http://jama.ama-assn.org/cgi/content/full/303/6/513-a

Correction

Citations

Topic collections
Contact me if this article is corrected.

Contact me when this article is cited.

Cardiovascular System; Radiologic Imaging; Surgery; Surgical Interventions; Endoscopy/ Minimally Invasive Surgery; Vascular Surgery; Surgical Interventions, Other; Radiologic Imaging, Other; Cardiovascular Disease/ Myocardial Infarction Contact me when new articles are published in these topic areas.
Subscribe

http://jama.com/subscribe

\section{Permissions}

permissions@ama-assn.org

http://pubs.ama-assn.org/misc/permissions.dtl

\section{Email Alerts}

http://jamaarchives.com/alerts

Reprints/E-prints

reprints@ama-assn.org 


\section{Comparing Endovascular and Open Repair of Abdominal Aortic Aneurysm}

To the Editor: The report of the short-term outcomes of the Open Versus Endovascular Repair (OVER) trial by Dr Lederle and colleagues ${ }^{1}$ provided little information regarding the endovascular procedures used for repair of abdominal aortic aneurysm (AAA). Although the open surgical procedure may have become standardized during the last 3 decades, with homogenous results regardless of the manufactured graft type, the same is not likely with the endovascular stent grafts.

The different types of endografts have diverse anatomical and morphological features leading to differing technical feasibility, varying types of construction, and differing materials. Therefore, they are made to treat different types of patients. The authors stated that all patients were eligible for both open surgical and endovascular procedures, but did not describe the specific endovascular inclusion criteria and the anatomical characteristics of the patients who were treated.

Moreover, the authors reported endoleaks in $25 \%$ of the endovascular group, resulting in a secondary procedure in $4.1 \%$ of patients. However, they did not give information regarding the actual types of endoleaks (which can vary from the "innocent" type II endoleaks to "aggressive" type I and type III endoleaks ${ }^{2}$ ), the percentages of endoleaks by the different types of endografts, or the fate of the leak and the aneurysm sac in the remaining $23.9 \%$ of the patients under observation.

Ilias Dalainas, MD, PhD

dalainas@freemail.gr

University of Athens

Athens, Greece

Financial Disclosures: None reported.

1. Lederle FA, Freischlag JA, Kyriakides TC, et al; Open Versus Endovascular Repair (OVER) Veterans Affairs Cooperative Study Group. Outcomes following endovascular vs open repair of abdominal aortic aneurysm: a randomized trial. JAMA 2009;302(14):1535-1542.

2. Dalainas I, Nano G, Casana R, Tealdi Dg D. Mid-term results after endovascular repair of abdominal aortic aneurysms: a four-year experience. Eur J Vasc Endovasc Surg. 2004;27(3):319-323.

To the Editor: Dr Lederle and colleagues ${ }^{1}$ conducted a randomized trial to compare endovascular vs open repair of AAA, showing lower perioperative mortality for endovascular repair. The early advantage of endovascular repair was not offset by increased mortality in the first 2 years after repair.

The atherosclerotic process is often not limited to a single arterial location, giving it a character of a systemic and generalized disease. More than 25 years ago, a study by Hertzer et $\mathrm{al}^{2}$ demonstrated that only $6 \%$ of patients with an AAA have a healthy coronary tree. In a study by Feringa et al, ${ }^{3}$ a group of patients who had vascular surgery and underwent preoperative cardiac testing had an asymptomatic ejection fraction of less than $40 \%$ or silent ischemia (new wall motion abnormalities) in $14 \%$ and $41 \%$ of the patients, respectively.

Although the atherosclerotic process may generally remain asymptomatic, surgical stress may elicit a rapid progression of the atherosclerotic disease. This progression is reflected by asymptomatic perioperative troponin T release, an important marker of underlying coronary artery disease. Studies have demonstrated prevalence of troponin T release of $10 \%$ after endovascular repair and 30\% after open repair, with up to $90 \%$ of the troponin T elevations asymptomatic. ${ }^{4}$ The occurrence of asymptomatic perioperative myocardial damage, assessed with troponin $\mathrm{T}$ measurements and continuous electrocardiographic monitoring for 72 hours, has been associated with a 2.3-fold increased risk for long-term mortality in patients who have had vascular surgery. ${ }^{4,5}$

Endovascular repair of AAA may result in a reduced perioperative stress response compared with open repair, which could explain the reduced short-term mortality rates. The disappearance of the early advantage of endovascular repair after 2 years could be explained by a high incidence of asymptomatic coronary artery disease, with an accelerated subclinical progression due to surgical stress that results in asymptomatic perioperative cardiac damage and reduced survival rates during long-term follow-up.

Jan-Peter van Kuijk, MD

Willem-Jan Flu, MD

Don Poldermans, MD

d.poldermans@erasmusmc.nl

Department of Anaesthesiology

Erasmus Medical Center Rotterdam

Rotterdam, the Netherlands

Financial Disclosures: None reported.

1. Lederle FA, Freischlag JA, Kyriakides TC, et al; Open Versus Endovascular Repair (OVER) Veterans Affairs Cooperative Study Group. Outcomes following endovascular vs open repair of abdominal aortic aneurysm: a randomized trial. JAMA. 2009;302(14):1535-1542.

2. Hertzer NR, Beven EG, Young JR, et al. Coronary artery disease in peripheral vascular patients: a classification of 1000 coronary angiograms and results of surgical management. Ann Surg. 1984;199(2):223-233.

GUIDELINES FOR LETTERS. Letters discussing a recent JAMA article will have the best chance of acceptance if they are received within 4 weeks of the article's publication date. Letters may have no more than 3 authors. They should not exceed 400 words of text and 5 references. Letters reporting original research should not exceed 600 words and 6 references. They may have no more than 5 authors. All letters should include a word count. Letters must not duplicate other material published or submitted for publication. Letters will be published at the discretion of the editors and are subject to editing and abridgment. A signed statement for authorship criteria and responsibility, financial disclosure, copyright transfer, and acknowledgment is required for publication. Letters not meeting these specifications are generally not considered. Before submitting a Research Letter, please review the Instructions for Authors (http://jama.com/instructions). Letters should be submitted via the JAMA online submission and review system at http:// manuscripts.jama.com (note: do not include "www" before the URL). For technical assistance, please contact jama-letters@jama-archives.org.

Letters Section Editor: Robert M. Golub, MD, Senior Editor.

(Reprinted) JAMA, February 10, 2010—Vol 303, No. $6 \mathbf{5 1 3}$ 
3. Feringa $\mathrm{HH}$, Elhendy $\mathrm{A}$, Karagiannis $\mathrm{SE}$, et al. Improving risk assessment with cardiac testing in peripheral arterial disease. Am J Med. 2007:120(6):531-538.

4. Winkel TA, Schouten O, van Kuijk JP, Verhagen HJ, Bax JJ, Poldermans D. Perioperative asymptomatic cardiac damage after endovascular abdominal aneurysm repair is associated with poor long-term outcome. J Vasc Surg. 2009;50(4): 749-754.

5. Mangano DT, Browner WS, Hollenberg M, London MJ, Tubau JF, Tateo IM The Study of Perioperative Ischemia Research Group. Association of perioperative myocardial ischemia with cardiac morbidity and mortality in men undergoing noncardiac surgery. N Engl J Med. 1990;323(26):1781-1788.

To the Editor: In their article reporting the short-term perioperative outcomes of the OVER trial, Dr Lederle and colleagues ${ }^{1}$ inaccurately stated, "All 109 lead proceduralists for aneurysm repair were vascular surgeons." They also commented, "Procedures in our trial were performed by experienced university-affiliated vascular surgeons," suggesting this as an explanation for improved perioperative outcomes in the OVER trial relative to the EVAR-1 and DREAM trials. These statements overlooked and obscured the contribution of many vascular interventional radiologists, some of whom were investigators in the trial.

In my own experience, participating in the care of these patients in 2 of the centers (George E. Wahlen VA Medical Center, Salt Lake City, Utah, and Puget Sound VA Medical Center, Seattle, Washington), the lead proceduralists, providing oversight and direction and personally performing the majority of the endovascular aneurysm repair procedures, were vascular interventional radiologists. In 2002, when randomization began in the OVER study, very few vascular surgeons had the training and experience to independently perform endovascular aneurysm repairs, most of which were being performed by vascular interventional radiologists. During the period of enrollment, between 2002 and 2007, vascular surgery fellowships increasingly included formal training in catheter intervention, including endovascular aneurysm repair. Therefore, toward the end of the enrollment period, vascular surgeons were more likely to perform these procedures independently.

Laura K. Findeiss, MD

wvvir@yahoo.com

Section of Vascular and Interventional Radiology

University of California at Irvine School of Medicine

Orange

Financial Disclosures: None reported

1. Lederle FA, Freischlag JA, Kyriakides TC, et al; Open Versus Endovascular Repair (OVER) Veterans Affairs Cooperative Study Group. Outcomes following endovascular vs open repair of abdominal aortic aneurysm: a randomized trial. JAMA. 2009;302(14):1535-1542

In Reply: We agree with Dr Dalainas that the different endovascular systems are made to treat somewhat different patients. This is why at randomization we recorded the system that would be used if patients were assigned to endovascular repair to ensure comparison with patients assigned to the appropriate open repair in the subgroup analysis. The inclusion criteria were as stated in the article, with the pertinent issues being the AAA diameter and the requirement that patients had to be considered a candidate for both procedures by the participating vascular surgeon and meet the manufacturer's indications for the endovascular system that would be used if so assigned. Although the manufacturer's indications are quite specific, the study inclusion criteria could not be because they had to accommodate endovascular systems that were not yet approved at the time the study was planned. We also intended that inclusion be as unrestricted and reflective of usual practice as possible. In response to Dalainas' request for more detail on endoleaks, our article focused on the comparison of clinical outcomes after open and endovascular repair, such as secondary procedures, some of which resulted from endoleaks. However, endoleaks per se are not a clinical outcome that can be meaningfully compared with open repair outcomes. Detailed descriptions of endoleaks and anatomic characteristics of enrolled patients may be included in future analyses.

In their discussion of "the disappearance of the early advantage of endovascular repair after 2 years," we are uncertain whether Dr van Kuijk and colleagues are referring to the earlier European trials, in which the survival curves converged, or to our study, in which the loss of statistical significance at 2 years resulted not from excess late deaths after endovascular repair but from the decrease in the relative difference in mortality rates as the total number of deaths increased, a phenomenon requiring no further biological explanation. We do not agree with an assumption that AAAs are a manifestation of the atherosclerotic process, as the preponderance of data appear to suggest a distinct etiology. ${ }^{1}$

We thank Dr Findeiss for calling attention to the role of interventional radiologists in our study, and apologize to her and her colleagues for failing to adequately acknowledge their contribution. Our data on lead proceduralists were provided by the centers and indicated the person responsible to the study for the procedure, and so may not have fully captured individual contributions. We have subsequently reviewed operative reports at the 6 centers with study-approved interventional radiologists and identified 42 endovascular repairs in which interventional radiologists had a major role. We are extremely grateful for their participation, and the expertise of these interventional radiologists clearly contributed to the success of the study.

Frank A. Lederle, MD

frank.lederle@va.gov

Veterans Affairs Medical Center

Minneapolis, Minnesota

Julie A. Freischlag, MD

Veterans Affairs Medical Center

Baltimore, Maryland

Tassos C. Kyriakides, PhD

Veterans Affairs Medical Center

West Haven, Connecticut

Financial Disclosures: None reported

1. Nordon IM, Hinchliffe RJ, Holt PJ, Loftus IM, Thompson MM. Review of current theories for abdominal aortic aneurysm pathogenesis. Vascular. 2009; 17(5):253-263.

C2010 American Medical Association. All rights reserved. 